\title{
Fontes de adubação orgânica no consórcio de coentro e rúcula em Cruz das Almas-
}

\section{BA}

\author{
Sources of organic fertilization in the consortium of coriander and arugula in Cruz das Almas-BA \\ Fuentes de fertilización orgánica em el consorcio de cilandro y rúcula en Cruz das Almas-BA
}

Recebido: 13/09/2021 | Revisado: 30/09/2021 | Aceito: 04/10/2021 | Publicado: 06/10/2021

Ana Paula da Silva Novaes

ORCID: https://orcid.org/0000-0003-2960-7650 Universidade Federal do Recôncavo da Bahia, Brasil

E-mail: annassilva18@gmail.com

Josué Pinheiro Machado

ORCID: https://orcid.org/0000-0002-4618-666X Universidade Federal do Recôncavo da Bahia, Brasil

E-mail: josuepadrao2012@ @otmail.com

Caliane da Silva Braulio

ORCID: https://orcid.org/0000-0003-3074-2876

Universidade Federal do Recôncavo da Bahia, Brasil

E-mail: caliane.braulio@gmail.com

Lorena da Paixão Oliveira

ORCID: https://orcid.org/0000-0003-4609-4746

Universidade Federal do Recôncavo da Bahia, Brasil

E-mail: lorena_dapaixao@hotmail.com

Ana Carolina da Silva Novaes

ORCID: https://orcid.org/0000-0001-7558-2576

Universidade Federal do Recôncavo da Bahia, Brasil

E-mail: kaah1869@gmail.com

Luís Cláudio Vieira Silva

ORCID: https://orcid.org/0000-0003-1337-8929

Universidade Estadual de Santa Cruz, Brasil

E-mail: luismstt@yahoo.com.br

Matheus Pires Quintela

ORCID: https://orcid.org/0000-0002-8096-6950

Universidade Federal do Recôncavo da Bahia, Brasil E-mail: matheus.quintela@ufrb.edu.br

\begin{abstract}
Resumo
Tendo como objetivo avaliar o efeito do consórcio e adubação orgânica na produção de coentro e rúcula. O experimento ocorreu na Fazenda Experimental da Universidade Federal do Recôncavo da Bahia (UFRB), na cidade de Cruz das Almas- Bahia. O delineamento utilizado foi em blocos ao acaso, em parcelas subdivididas no espaço em $3 \times 3$ com cinco repetições. Após 33 dias do semeio da rúcula e 35 do coentro, foram avaliadas a altura, a massa seca e fresca da parte aéreas das plantas. Os estercos utilizados foram o bovino e o de galinha, e as espécies vegetais foram rúcula cv. Cultivada e coentro cv. Verdão. Quando avaliado os tratamentos de forma individual os resultados demonstraram a ineficiência do consórcio para apenas a cultura da rúcula. O coentro se desenvolveu bem no consórcio, não apresentando diferença quando comparado ao monocultivo, mas a rúcula no consórcio apresentou baixa produção quando comparado ao cultivo solteiro. Quanto à adubação, apenas o cultivo solteiro da rúcula apresentou diferença, sendo o esterco de galinha o melhor para produção. Para uso eficiente da terra (UET) apenas o consórcio com esterco de gado apresentou índice superior á 1,0; o monocultivo da rúcula adubada com esterco de galinha apresentou maior receita bruta e melhor renda liquida. $\mathrm{O}$ custo operacional foi maior em todos os tratamentos que envolveram o esterco bovino. Considerando os índices econômicos, conclui-se que o consórcio entre rúcula e coentro não é viável quando adubado com o esterco que proporcionou melhor desempenho no consórcio que foi o esterco bovino.
\end{abstract}

Palavras-chave: Esterco bovino; Esterco de galinha; Monocultivo.

\section{Abstract}

Aiming to evaluate the effect of intercropping and organic fertilization on the production of coriander and arugula. The experiment took place at the Experimental Farm of the Federal University of Recôncavo da Bahia (UFRB), in the city of Cruz das Almas-Bahia. The design used was randomized blocks, in split-plots in $3 \times 3$ space with five 
replications. After 33 days of sowing of rocket and 35 of coriander, height, dry and fresh mass of aerial parts of the plants were evaluated. The manure used was cattle and chicken, and the vegetable species were rocket cv. Cultivated and coriander cv. Summer. When the treatments were evaluated individually, the results showed the inefficiency of the intercropping for only the arugula crop. Coriander developed well in the intercropping, showing no difference when compared to the monoculture, but the rocket in the intercropping showed low production when compared to the single crop. As for fertilization, only the single arugula crop showed a difference, with chicken manure being the best for production. For efficient land use (UET) only the intercropping with cattle manure presented an index higher than 1.0; the monoculture of rocket fertilized with chicken manure showed higher gross income and better net income. The operating cost was higher in all treatments involving cattle manure. Considering the economic indices, it is concluded that the intercropping between arugula and coriander is not viable when fertilized with the manure that provided better performance in the intercropping that was the bovine manure.

Keywords: Cattle manure; Chicken manure; Monoculture.

\section{Resumen}

Con el objetivo de evaluar el efecto de los cultivos intercalados y la fertilización orgánica en la producción de cilantro y rúcula. El experimento se llevó a cabo en la Granja Experimental de la Universidad Federal de Recôncavo da Bahia (UFRB), en la ciudad de Cruz das Almas-Bahia. El diseño utilizado fue de bloques al azar, en parcelas divididas en un espacio de $3 \times 3$ con cinco repeticiones. Luego de 33 días de siembra de rúcula y 35 de cilantro, se evaluó altura, masa seca y fresca de partes aéreas de las plantas. El estiércol utilizado fue ganado y pollo, y las especies vegetales fueron rúcula cv. Cultivado y cv. De cilantro. El verano. Cuando los tratamientos se evaluaron individualmente, los resultados mostraron la ineficiencia del cultivo intercalado solo para el cultivo de rúcula. El cilantro se desarrolló bien en el cultivo intercalado, sin mostrar diferencias en comparación con el monocultivo, pero la rúcula en el cultivo intercalado mostró una producción baja en comparación con el monocultivo. En cuanto a la fertilización, solo el cultivo de rúcula mostró una diferencia, siendo el estiércol de pollo el mejor para la producción. Para el uso eficiente de la tierra (UET) solo el cultivo intercalado con estiércol de ganado presentó un índice superior a 1.0; el monocultivo de rúcula fertilizada con estiércol de pollo mostró mayores ingresos brutos y mejores ingresos netos. El costo operativo fue mayor en todos los tratamientos que involucraron estiércol de ganado. Considerando los índices económicos, se concluye que el intercalado entre rúcula y cilantro no es viable cuando se fertiliza con el estiércol que mejor desempeño en el intercalado que fue el estiércol bovino.

Palabras clave: Estiércol de ganado; Estiércol de pollo; Monocultivo.

\section{Introdução}

Nos últimos anos com a preocupação das pessoas com alimentação saudável há um aumento pela procura de alimentos de qualidade, sem utilização de produtos químicos capazes de prejudicar a saúde (Sediyama; Santos e Lima, 2014).

No Brasil a agricultura sem o uso de produtos químicos sintéticos é praticada em sua maioria pelos pequenos agricultores, sendo que a maioria deles cultiva hortaliças (Pelá et al., 2017). Plantar hortaliças é uma boa opção para o agricultor por serem de ciclo curto e possibilitar um rápido retorno financeiro, porém a escolha da espécie a ser cultivada deve estar relacionada às condições climáticas, mas principalmente, a preferência dos consumidores locais (Bezerra, 2003).

De acordo com o último Censo Agropecuário (IBGE, 2017), a agricultura familiar corresponde a $77 \%$ dos estabelecimentos rurais no Brasil, embora só detenha $23 \%$ da área total de terras do país, representando $23 \%$ do valor bruto de produção, com $67 \%$ de pessoal ocupado no meio rural. Neste mesmo censo foi informado que, em média cada hectare gera em torno de 3 a 6 empregos de forma direta e indireta, sendo uma das principais fornecedoras de alimentos básicos à alimentação do brasileiro.

O consórcio de culturas é uma forma de plantio que pode ser implementada pelos agricultores, especialmente os familiares, com a proposta de cultivar duas ou mais espécies agrícolas na mesma área, aumentando a diversidade de plantas e produtos a serem ofertados no mercado, gerando assim maior retorno econômico ao produtor (Silva et al., 2013).

A utilização da consorciação de culturas agrícolas está sendo cada vez mais promovidos por minimizar os danos ambientais causados pela monocultura, danos provocados pelo uso massivo de defensivos químicos para conter insetos praga, doenças e plantas espontâneas, além do uso desordenado de adubos químicos para manter a fertilidade do solo, falta de cobertura e revolvimento em excesso do solo (Oliveira et al., 2010).

Pesquisas realizadas vêm demonstrando que o sistema de consórcio é valido para produção de hortaliças, resultando 
em benefícios na produtividade das culturas, aumentando a produção quando comparada ao monocultivo, além de reduzir danos causados desde o solo até as plantas, como erosão do solo e controle de pragas e doenças, sendo considerada uma técnica sustentável (Teixeira; Mota \& Silva, 2005).

Estudos realizados indicam que as culturas de coentro (Coriandrum sativum L.) e rúcula (Eruca sativa L.) respondem bem ao sistema de consorciação, Lima et al. (2014) conferiram que as plantas de rúcula e coentro quando associadas entre si e à cultura da alface contribuem com maior Uso Eficiente da Terra (UET), atribuindo ganho econômico, independente do arranjo espacial escolhido. As culturas de rúcula e coentro são boas opções de hortaliças para serem usadas no cultivo consorciado, ambas têm facilidade em ser comercializadas, sendo boas para a economia, diversidade de uso, além de serem cultivadas facilmente pelo agricultor familiar (Santos et al., 2014).

Mesmo sabendo dos inúmeros benefícios do consorcio, há por parte dos produtores dificuldades na instalação do sistema, dúvidas sobre arranjos e culturas a serem utilizadas e até mesmo informações de como a adubação interfere na obtenção do sucesso ao final do procedimento. Visto isso, o presente trabalho tem relevância ao desenvolver pesquisa para descobrir se há eficiência no consorcio entre coentro e rúcula, e o melhor esterco animal como forma de adubo orgânico para as referidas culturas.

O presente trabalho teve como objetivo avaliar o efeito do consórcio e adubação orgânica na produção de hortaliças, em especial o consórcio entre coentro e rúcula.

\section{Metodologia}

O experimento foi conduzido no período de novembro a dezembro de 2019, na Fazenda Experimental Vegetal da Universidade Federal do Recôncavo da Bahia (UFRB) - Campus Cruz das Almas - BA. A região possui um clima do tipo Am úmido a subúmido, com as normais climatológicas do município para o período de 1981 a 2010: 1117, 4 mm de chuva; 1016,0 hPa de pressão atmosférica; $29,1{ }^{\circ} \mathrm{C}, 20,5{ }^{\circ} \mathrm{C}$ e $24,0{ }^{\circ} \mathrm{C}$ de temperaturas máximas, mínima e média do ar, respectivamente; $81,0 \%$ de umidade relativa do ar; insolação total de $2.282,7$ h e $127,9 \mathrm{~mm}$ de evapotranspiração potencial (INMET, 2019). O solo da área foi classificado como Latossolo Amarelo Distrocoeso com textura média, dados sobre a análise química do solo estão dispostos na Tabela 1.

Tabela 1 - Atributos químicos do solo na camada de 0,00 - 0,20 m localizado na Universidade Federal do Recôncavo da Bahia em Cruz das Almas-BA.

\begin{tabular}{|c|c|c|c|c|c|c|c|c|c|c|c|}
\hline $\mathrm{pH}$ & $\mathrm{P}$ & $\mathrm{K}$ & $\mathrm{Ca}$ & $\mathrm{Mg}$ & $\mathrm{H}+\mathrm{Al}$ & $\mathrm{Al}$ & $\mathrm{Na}$ & $\mathrm{S}$ & CTC & $\mathrm{V}$ & M.O \\
\hline $\mathrm{H} 2 \mathrm{O}$ & \multicolumn{7}{|c|}{ mg dm- ${ }^{3}$} & $\%$ & $\mathrm{~g} \mathrm{dm}^{-3}$ & & \\
\hline 5,18 & 12 & 44 & 1,3 & 0,7 & 2,47 & 0,1 & 0,1 & 2,21 & 4,68 & 47,22 & 13,2 \\
\hline
\end{tabular}

Fonte: Autores (2019).

As espécies utilizadas foram coentro cultivar verdão e a rúcula cultivar cultivada. Adquiridas no comércio da cidade de Cruz das Almas-BA. Ambas foram semeadas em canteiros a uma profundidade de $2 \mathrm{~cm}$. As semeaduras ocorreram simultaneamente, sendo realizado o desbaste, tanto do coentro como da rúcula aos 15 dias após a semeadura (DAS).

O delineamento utilizado foi em blocos ao acaso, em parcelas subdivididas no espaço em arranjo 3 x 3 com cinco repetições, totalizando 45 parcelas. Na parcela principal foram casualizados dois tipos de adubação: A1-adubação com esterco bovino, A2- adubação com esterco de galinha e A3- sem adubação. As parcelas foram divididas em três sub-parcelas para os 
diferentes tipos de cultivos. Na sub-parcela ficaram casualizados três combinações de plantio: P1- monocultivo do coentro $(0,20 \times 0,05 \mathrm{~m}), \mathrm{P} 2$ - monocultivo de rúcula $(0,20 \times 0,05 \mathrm{~m})$ e P3- consórcio coentro e rúcula $(0,10 \times 0,05 \mathrm{~m})$.

A sub-parcela ficou representada por uma porção do canteiro medindo $1,20 \mathrm{~m}$ de largura por 1,50 m de comprimento, com uma área de 1,80 m2. A bordadura foi composta pelas linhas externas de cada parcela e uma planta do início e final de cada uma das linhas centrais, perfazendo uma parcela útil de 1,40 m. Nos consórcios, a semeadura da rúcula foi realizada no sentido longitudinal do canteiro, nas entrelinhas do coentro.

O preparo da área foi feito de forma manual e após a limpeza foram levantados cinco canteiros de 14 metros de comprimento e 1,20 m de largura cada um. Os canteiros foram divididos em três parcelas de 5,4 $\mathrm{m}^{2}$, cada uma recebeu um tipo de adubação, ficando separadas por 0,25 m para evitar possível contaminação entre os canteiros. Para adubação foi considerada a indicação de 30 t/ha de esterco bovino e 10 t/ha de esterco de galinha.

Para adubação de cobertura realizada aos 15 dias após a semeadura (DAS) foi utilizado a metade da quantidade da adubação indicada no plantio. No total somando a adubação de plantio mais a de cobertura foram utilizados $121,5 \mathrm{~kg}$ de esterco bovino e 40,5 $\mathrm{kg}$ de esterco de galinha.

A adubação de base foi feita de forma manual com distribuição e incorporação dos compostos orgânicos nas áreas específicas e a adubação de cobertura foi aplicada nas entrelinhas das plantas.

O manejo de plantas espontâneas foi realizado com capinas manuais e as irrigações foram efetuadas diariamente durante todo ciclo das culturas no período da manhã e tarde. O manejo das formigas foi realizado com a utilização da manipueira. A colheita da rúcula e do coentro ocorreu aos 33 e 35 dias respectivamente após a semeadura.

Nas culturas estudadas, avaliações morfológicas foram realizadas em amostras de 15 plantas colhidas aleatoriamente dentro de cada parcela útil. As características avaliadas para o coentro e rúcula: altura (H) de plantas, massa fresca (MFPA) e seca (MSPA) da parte aérea das plantas. A altura da planta foi obtida através de uma régua, a partir do nível do solo até a extremidade das folhas mais altas e expressas em $\mathrm{cm}$; as massas frescas e secas foram determinadas em balança analítica e os dados expressos em g; a massa seca foi obtida após as plantas serem colocadas em estufa de circulação forçada de ar a temperatura de $65^{\circ} \mathrm{C}$, até atingir massa constante.

Os indicadores agroeconômicos usados para medir a eficiência dos sistemas consorciados foram de acordo com (Beltrão et al., 1984), sendo obtido o índice de uso eficiente da terra (UET), receita bruta (RB), custo operacional (CO) e renda líquida (RL). O índice UET é dado pela seguinte expressão: (Icoentro/Scoentro) + (Irúcula/Srúcula), onde I e S representam as produtividades dos sistemas consorciado e solteiro, respectivamente, de cada cultura componente sendo definido como a área relativa de terra sob condições de plantio isolado, que é requerida para proporcionar as produtividades alcançadas no consórcio.

A estimativa da produtividade por hectare foi realizada para $70 \%$ da área plantada, em virtude de $30 \%$ dela ser composta de área de trânsito e corredores. A receita bruta $(\mathrm{RB}) \mathrm{em} \mathrm{R} \$ \mathrm{ha}^{-1}$ foi obtida através do produto da produção comercial das culturas em consórcio e cultivo solteiro $\left(\mathrm{kg} \mathrm{ha}^{-1}\right)$, pelo preço médio praticado na época da colheita nos principais mercados locais e regionais. Para custo operacional $\left(\mathrm{R} \$ \mathrm{ha}^{-1}\right)$ considerou-se os desembolsos efetivos realizados pelo produtor durante o ciclo produtivo das culturas englobando despesas com mão-de-obra e insumos. A renda líquida (RL) (R\$ ha $\left.{ }^{-1}\right)$ foi calculada subtraindo-se da receita bruta, os custos de produção, provenientes de insumos mais serviços.

Como suporte metodológico para a realização da pesquisa, foi utilizado como base a metodologia de Pereira et al. (2018).

De posse dos dados foi realizada a análise de variância. Para as variáveis que mostraram efeito significativo dos tratamentos pelo teste $\mathrm{F}$, procedeu a comparação de médias pelo teste de Tukey a 5\% de probabilidade. Para execução das análises estatísticas foi utilizado o programa R (R Core Team, 2018). 


\section{Resultados e Discussão}

\subsection{Coentro}

Os resultados da comparação entre as adubações orgânicas na altura de plantas, massa fresca e seca da parte aérea de coentro encontram-se na Tabela 2. Para altura, massa seca e fresca das plantas do coentro a adubação foi o único fator que demostrou efeito significativo.

Tabela 2. Altura de plantas $(\mathrm{H})$ em $\mathrm{cm}$, massa seca e fresca da parte aérea do coentro (MFPA) e (MSPA) em gramas por metro quadrado, nas condições de adubação orgânica. Cruz das Almas, UFRB, 2019.

\begin{tabular}{lccc}
\hline Tratamentos & $\mathrm{H}(\mathrm{cm})$ & MFPA $\left(\mathrm{g} / \mathrm{m}^{2}\right)$ & MSPA $\left(\mathrm{g} / \mathrm{m}^{2}\right)$ \\
\hline Esterco bovino & $16,21 \mathrm{a}$ & $253,70 \mathrm{a}$ & $32,00 \mathrm{a}$ \\
Esterco de galinha & $16,37 \mathrm{a}$ & $316,80 \mathrm{a}$ & $32,20 \mathrm{a}$ \\
Sem adubação & $8,00 \mathrm{~b}$ & $80,30 \mathrm{~b}$ & $9,10 \mathrm{~b}$ \\
\hline CV1(\%) & 28.30 & 25,80 & 63,81 \\
CV2(\%) & 25.99 & 25,93 & 69,88 \\
\hline
\end{tabular}

Médias seguidas pela mesma letra, na coluna, não diferem entre si ao nível de 5\% de probabilidade, pelo teste de Tukey. Fonte: Autores (2019).

Os sistemas de cultivo não causaram efeitos significativos, demostrando que não houve competição da cultura da rúcula com coentro. Houve diferença entre a testemunha não adubada e os tratamentos adubados, que foram iguais entre si. Portanto, ambos os estercos demostraram ser eficientes para cultivo do coentro. Para o agricultor o que deve ser levado em consideração é o custo dos estercos, optando pelo mais barato economicamente.

Mesmo resultado foi encontrado por Oliveira et al. (2013) em que a altura do coentro não diferiu entre os tratamentos utilizados quando consorciado com a cultura da cenoura e rúcula. Lima et al. (2014) também não encontraram nenhuma diferença nas características avaliadas na cultura do coentro consorciada á rúcula e alface. Resultados semelhantes foram encontrados por Grangeiro et al. (2008) no consórcio do coentro e da rúcula e os resultados indicaram que o coentro não sofreu prejuízos quando associado a rúcula, concluindo que o consórcio demostrou ser viável de forma agronômica.

Avaliando o desenvolvimento do coentro e acelga adubados com diferentes fertilizantes orgânicos (esterco bovino, esterco de frango e esterco ovino), Silva et al. (2017) confirmaram que o esterco de frango possibilitou os melhores resultados para as duas culturas, produzindo plantas com cores vivas, aroma mais forte, melhor desenvolvimento de caules e folhas.

O esterco bovino foi o segundo melhor esterco, os autores explicam que isto é devido a sua composição de NPK. Para a massa seca da parte aérea não houve diferença entre os tratamentos adubados com ambos os estercos e entre os sistemas de cultivo, notando-se que a testemunha diferiu na adubação, apresentando a menor média (Tabela 3). 
Tabela 3. Massa seca da parte aérea (MSPA) (g/planta) de plantas de coentro, nas condições de consórcio e adubação orgânica. Cruz das Almas, UFRB, 2019.

\begin{tabular}{lc}
\hline Tratamentos & Massa seca da parte aérea (g/planta) \\
\hline Adubação & $0,24 \mathrm{a}$ \\
Esterco bovino (A1) & $0,24 \mathrm{a}$ \\
Esterco de galinha (A2) & $0,07 \mathrm{~b}$ \\
Sem adubação & \\
\hline Sistema de cultivo & $0,25 \mathrm{a}$ \\
Coentro monocultivo (P1) & $0,11 \mathrm{a}$ \\
Coentro + Rúcula (P3) & 47,85 \\
\hline CV 1 $(\%)$ & 55,63 \\
CV2(\%)
\end{tabular}

Médias seguidas pela mesma letra, na coluna, não diferem entre si ao nível de 5\% de probabilidade, pelo teste de Tukey. Fonte: Autores (2019).

Confirmando a eficiência da adubação orgânica, Cerqueira et al. (2019) avaliando o cultivo de coentro adubado com esterco bovino e químico, constataram que o adubo orgânico foi capaz de proporcionar melhor desenvolvimento á cultura do coentro quando comparado a adubação química que foi significativa apenas no teor de clorofila, enquanto que para altura da planta e peso seco da haste somente quando houve presença do esterco bovino.

A Tabela 3 reafirma o desenvolvimento positivo do coentro em consórcio e monocultivo e seu bom desenvolvimento quando adubado com os respectivos estercos.

\subsection{Rúcula}

O resultado da comparação entre os sistemas de cultivos e entre as adubações orgânicas na altura de plantas encontrase na Tabela 4.

Tabela 4. Altura de plantas (H) nas condições de consórcio e adubação orgânica. Cruz das Almas, UFRB, 2019.

\begin{tabular}{lcc}
\hline Cultivo & H (cm) & NF \\
\hline Esterco bovino & $16,81 \mathrm{a}$ & $7,22 \mathrm{~b}$ \\
Esterco de galinha & $18,92 \mathrm{a}$ & $10,47 \mathrm{a}$ \\
Sem adubação & $14,10 \mathrm{~b}$ & $5,89 \mathrm{~b}$ \\
\hline CV1(\%) & 12,32 & 15,62 \\
CV2(\%) & 9,10 & 17,46
\end{tabular}

Médias seguidas pela mesma letra, na coluna, não diferem entre si ao nível de 5\% de probabilidade, pelo teste de Tukey. Fonte: Autores (2019).

Para altura da planta e número de folhas de rúcula não houve interação dos métodos de cultivos com as adubações testadas, o único fator que demonstrou efeito significativo foi as adubações.

Para altura de plantas os estercos utilizados não diferiram entre si, diferindo das parcelas não adubadas. Resultados corroboram com os de Lima et al. (2014) para altura não houve interferência com a cultura consorciada. Para Salles et al. (2017) os melhores resultados foram encontrados quando utilizado o esterco de galinha de forma isolada e com esterco bovino 
e torta de filtro na produção da rúcula.

Os melhores resultados encontrados nesse trabalho na cultura da rúcula quando adubada com esterco de galinha pode ser explicado pelo alto teor de nitrogênio presente no esterco, que de acordo com Barros Júnior et al. (2009) a sua ausência causou redução em 70\% na produção de rúcula. Resultados semelhantes foram encontrados por Corrêa et al. (2010) no cultivo de orégano (Origanum vulgare L.) adubado com esterco bovino e avícola, a maior produção de folhas ocorreu na adubação com esterco de aves devido ao fato do esterco conter em sua composição cerca do dobro de $\mathrm{N}$ contido no esterco bovino.

Para a variável massa fresca e seca de rúcula houve efeito da interação entre os sistemas de cultivo e a adubação orgânica, conforme dados da Tabela 5.

O cultivo consorciado apresentou as menores médias, demonstrando que o consórcio não foi benéfico para a rúcula nas duas variáveis analisadas, podendo ser observado que o monocultivo de rúcula foi significativamente maior independente da utilização de adubação ou da não utilização.

Tabela 5. Massa fresca e seca (MFPA) e (MSPA) $\left(\mathrm{g} / \mathrm{m}^{2}\right)$ de rúcula, nas condições de consórcio e adubação orgânica. Cruz das Almas, UFRB, 2019.

\begin{tabular}{|c|c|c|c|c|c|c|}
\hline \multirow{2}{*}{ Sistema de cultivo } & \multicolumn{4}{|c|}{ Massa fresca $\left(\mathrm{g} / \mathrm{m}^{2}\right)$} & \multicolumn{2}{|c|}{ Massa Seca $\left(\mathrm{g} / \mathrm{m}^{2}\right)$} \\
\hline & Esterco bovino & Esterco de galinha & Sem adubação & Esterco bovino & Esterco de galinha & Sem adubação \\
\hline Monocultivo de rúcula & $1079,80 \mathrm{Ab}$ & $1977,20 \mathrm{Aa}$ & $717,60 \mathrm{Ab}$ & $108,40 \mathrm{Ab}$ & $197,00 \mathrm{Aa}$ & $89,20 \mathrm{Ab}$ \\
\hline $\begin{array}{c}\text { Consórcio coentro } \\
\text { rúcula }\end{array}$ & $258,28 \mathrm{Ba}$ & $424,40 \mathrm{Ba}$ & $144,76 \mathrm{Ba}$ & $24,80 \mathrm{Ba}$ & $41,68 \mathrm{Ba}$ & $17,84 \mathrm{Ba}$ \\
\hline CV $1(\%)$ & & 33,48 & & & 36,87 & \\
\hline $\mathrm{CV} 2(\%)$ & & 33,10 & & & 41,80 & \\
\hline
\end{tabular}

Médias seguidas pela mesma letra, na coluna, não diferem entre si ao nível de 5\% de probabilidade, pelo teste de Tukey. Fonte: Autores (2019).

Resultados semelhantes foram encontrados por Cavalcante (2019) no cultivo consorciado de rúcula com caupihortaliça, foi verificado que a melhor opção para cultivar a rúcula seria o monocultivo, pois esse apresentou efeito positivo na produção quando comparado ao consórcio devido à competição entre as plantas.

Também foi verificado por Oliveira et al. (2010) que o consórcio de rúcula e alface prejudica o desenvolvimento da rúcula e os autores concluem que esse prejuízo é devido a competição por elementos abióticos.

Um fator que pode ter contribuído para a baixa produtividade da rúcula quando consorciada foi o menor espaçamento entre as culturas, o cultivo adensado impossibilitou o desenvolvimento das plantas de rúcula, deixando as folhas sem espaço para se expandir. Quanto maior o espaçamento de plantas no cultivo de rúcula, melhor é a sua produção (Freitas, 2009). Isso pode estar ligado aos resultados da rúcula neste trabalho que quando consorciada teve um menor espaço para o seu desenvolvimento o que levou ao menor rendimento comparado ao monocultivo. Silva et al. (2017) complementa que no consórcio é preciso ter espaço para as plantas se desenvolverem, pois, o adensamento impede a cooperação com a cultura companheira e contribui para competição entre elas.

A alta temperatura pode ter sido outro fator que interferiu no desenvolvimento da rúcula em consórcio, a cultura é adaptada a temperaturas amenas e foi cultivada no período primavera- verão onde ocorrem dias com elevadas temperaturas, as culturas podem ter competido pelo elemento essencial, a água.

Para a adubação aplicada verifica-se que não houve efeito para a variável massa fresca e seca da parte aérea em consórcio sendo verificado apenas no monocultivo da rúcula em que o esterco de galinha demonstrou ser o adubo que 
possibilitou os maiores valores para massa fresca e seca (Tabela 5).

Vários outros trabalhos realizados por pesquisadores com consórcio sendo a rúcula um dos componentes desse consórcio apresentaram semelhança ao observado no trabalho como por Grangeiro et al. (2007) consorciando a rúcula com a beterraba, que verificaram o menor rendimento no consórcio de massa fresca e seca, alegando que pode ser devido a competição por luz, pois no início o crescimento da rúcula é rápido e o sombreamento do coentro sob a rúcula pode ter atrapalhado o seu desenvolvimento.

E por Heredia et al. (2006) que constataram que o monocultivo com a cama-de-frango possibilitou maior massa fresca para cultura da rúcula quando esta foi consorciada com cebolinha. Spósito et al. (2015) obtiveram resultados diferentes aos encontrados no presente trabalho avaliando o desenvolvimento da rúcula sob adubação com cinco tipos de estercos animal onde o esterco de galinha proporcionou baixa produção até mesmo quando comparado ao tratamento testemunha. Os autores explicam que o ocorrido pode estar relacionado ao excesso de nutrientes no solo, pois, a área havia sido adubada antes, o que dificultou a eficácia do nitrogênio presente no esterco. Segundo Oliveira et al. (2009) a alta quantidade de nutrientes no solo prejudica a produtividade das plantas.

\subsection{Indicadores de eficiência agronômica e econômica}

Segundo a Tabela 6, o melhor uso eficiente da terra (UET) ocorreu quando foi estabelecido o consórcio entre coentro e rúcula adubados com o esterco bovino, sendo $20 \%$ maior em relação ao monocultivo. Já para o consórcio coentro e rúcula adubados com esterco de galinha e sem adubação o UET ficou abaixo dos encontrados no monocultivo.

Tabela 6. Índices de eficiência agronômica (UET) e econômica (Custo operacional, Receita bruta e Renda líquida) nas condições de consórcio e adubação orgânica, entre coentro e rúcula. Cruz das Almas, UFRB, 2019.

\begin{tabular}{lcccc}
\hline \multicolumn{1}{c}{ Tratamentos } & $\mathrm{UET}$ & $\begin{array}{c}\text { Receita bruta } \\
\left(\mathrm{R} \$ \mathrm{ha}^{-1}\right)\end{array}$ & $\begin{array}{c}\text { Custo operacional } \\
\left(\mathrm{R} \$ \mathrm{ha}^{-1}\right)\end{array}$ & $\begin{array}{c}\text { Renda líquida } \\
\left(\mathrm{R} \$ \mathrm{ha}^{-1}\right)\end{array}$ \\
\hline Coentro + Esterco bovino & 1 & $\mathrm{R} \$ 6.798,75$ & $\mathrm{R} \$ 6.534,60$ & $\mathrm{R} \$ 264,15$ \\
Coentro + Esterco de galinha & 1 & $\mathrm{R} \$ 9.408,00$ & $\mathrm{R} \$ 5.764,60$ & $\mathrm{R} \$ 3.643,40$ \\
Coentro + Sem adubação & 1 & $\mathrm{R} \$ 2.848,13$ & $\mathrm{R} \$ 4.854,60$ & $\mathrm{R} \$ 2.006,48$ \\
Rúcula + Esterco bovino & 1 & $\mathrm{R} \$ 37.793,00$ & $\mathrm{R} \$ 6.812,00$ & $\mathrm{R} \$ 30.981,00$ \\
Rúcula + Esterco de galinha & 1 & $\mathrm{R} \$ 69.202,00$ & $\mathrm{R} \$ 6.042,00$ & $\mathrm{R} \$ 63.160,00$ \\
Rúcula + Sem adubação & 1 & $\mathrm{R} \$ 25.116,00$ & $\mathrm{R} \$ 5.132,00$ & $\mathrm{R} \$ 19.984,00$ \\
Consórcio + Esterco bovino & 1,20 & $\mathrm{R} \$ 15.560,30$ & $\mathrm{R} \$ 7.044,60$ & $\mathrm{R} \$ 8.515,70$ \\
Consórcio + Esterco de galinha & 0,98 & $\mathrm{R} \$ 22.078,00$ & $\mathrm{R} \$ 6.274,60$ & $\mathrm{R} \$ 15.803,40$ \\
Consórcio + Sem adubação & 0,91 & $\mathrm{R} \$ 7.072,10$ & $\mathrm{R} \$ 5.364,60$ & $\mathrm{R} \$ 1.707,50$ \\
\hline
\end{tabular}

Fonte: Autores (2019).

Oliveira (2012) avaliando o consórcio de rúcula x coentro x cenoura adubadas com diferentes quantidades de jitirana e sob diferentes densidades de plantas, obteve UET superior a 1,0 em todos os consórcios, demonstrando que em todas as combinações de densidades populacionais houve uso eficiente dos recursos ambientais disponíveis.

A maior receita bruta foi da rúcula em monocultivo adubada com esterco de galinha com $\mathrm{R} \$ 69.202,00$, também com maior renda líquida $\mathrm{R} \$ 63.160,00$. Estes valores são explicados devido ao valor agregado da cultura da rúcula em relação ao coentro.

A renda liquida foi maior em todos monocultivos de rúcula, sendo maior a adubada com esterco de galinha, em segundo com esterco bovino. Entre os tratamentos o cultivo sem adubação chamou atenção por apresentar uma das rendas mais 
altas, até mesmo quando comparado ao cultivo consorciado independentemente da adubação.

O consórcio adubado com esterco bovino que apresentou melhor UET entre os tratamentos foi o que também teve maior custo operacional, devido ao custo na aquisição de sementes de mais uma cultura e do esterco bovino, que apesar de ser mais barato quando comparado ao esterco de galinha, foi utilizado em maior quantidade.

Pode ser observada na Tabela 6, que os valores das despesas expressas pelo custo operacional são sempre maiores quando se tem o envolvimento do esterco bovino. Embora o consórcio com esterco bovino tenha apresentado menor ganho econômico quando comparado ao cultivo solteiro o mesmo apresentou melhor (UET) demonstrando assim que durante o período de consorciação as plantas fizeram uso dos recursos ambientais disponíveis.

As plantas quando consorciadas não apresentaram incidência de pragas, nem doenças. Nas parcelas com consórcio houve aparecimento de joaninhas que são insetos que atuam como inimigos naturais impedindo o desenvolvimento de insetos indesejados (Togni et al., 2009).

\section{Conclusão}

O consórcio entre coentro e rúcula adubado com esterco bovino apresentou o melhor uso eficiente da terra. O monocultivo da rúcula adubado com esterco de galinha apresentou a melhor renda líquida. Apesar do consórcio adubado com o esterco bovino resultar em UET positivo, economicamente demonstrou ser inviável pelo fato de utilizar o esterco em maior quantidade, elevando o valor empregado ao insumo.

Sugerimos, a realização de trabalhos futuros com avaliação de diferentes espaçamentos para estabelecer a melhor distância entre a rúcula e o coentro, como também doses de esterco bovino, afim de definir uma dose recomendada para o consórcio entre coentro e rúcula, na qual possibilite o fornecimento de nutrientes necessário para o crescimento vegetal, viabilize o emprego do insumo e contribua para a sustentabilidade agrícola.

\section{Agradecimentos}

A Universidade Federal do Recôncavo da Bahia, a CAPES (Coordenação de Aperfeiçoamento de Pessoal de Nível Superior) e a FAPESB (Fundação de Amparo à Pesquisa do Estado da Bahia) pela concessão de bolsas.

\section{Referências}

Bomfim, J. M. F. (2017). Pegada hídrica e desempenho econômico da cultura do coentro (Coriandrum sativum L.) no agreste sergipano. Dissertação (Mestrado em Desenvolvimento e Meio Ambiente) - Universidade Federal de Sergipe. Mestre pelo Programa de Pós-Graduação em Desenvolvimento e Meio Ambiente da Universidade Federal de Sergipe, 80.

Cerqueira, D. C. O., Ferro, M. G. F., Silva, P. C., Silva, T. S. S., Santos Neto, A. L. \& Souza, A. A. (2019). Desempenho de plantas de coentro adubadas com doses de esterco bovino e fertilizante químico. Revista Ambientale. 11, 1-11.

Cavalcante, F. L. (2019). Viabilidade agronômica do consórcio de caupi-hortaliça com rúcula sob adubação orgânica. Dissertação (Mestrado em Sistemas Agroindustriais) Universidade Federal de Campina Grande, 44.

Linhares, P. C. F., Pereira, M. F. S., Moreira, J. C., Paiva, A. C. C., Assis, J. P. \& Sousa, R. P. (2015). Rendimento do coentro (Coriandrum sativum L.) adubado com esterco bovino em diferentes doses e tempos de incorporação no solo. Revista Brasileira de Plantas Medicinais, $17(3), 462-7$.

Oliveira Filho, A. F., Bezerra, F. T. C., Pitombeira, J. B., Dutra, A. S \& Barros, G. L. (2016). Eficiência agronômica e biológica nos consórcios da mamoneira com feijão-caupi ou milho. Revista Ciência Agronômica, 47 (4), 729-736.

Oliveira, A. M. Produção agroecológica do consórcio de rúcula com rabanete sob diferentes fontes de adubos orgânicos. (2019).. Dissertação (Mestrado em Sistemas Agroindustriais)- Universidade Federal de Campina Grande, 51.

Pelá, A., Silva Júnior, G. S., Silva, R. C. D, Silva, C. S. \& Pelá, G. M. (2017). Produção e teor de nitrato em rúcula sob adubação orgânica com cama de frango e esterco bovino. Revista Verde de Agroecologia e Desenvolvimento Sustentável, 12 (1), 48-54.

Pereira, A. S., Shitsula, D. M., Perreira, F. J. \& Shitsuka, R. (2018). Metodologia da pesquisa científica. UFSM. 
Research, Society and Development, v. 10, n. 13, e118101320548, 2021

(CC BY 4.0) | ISSN 2525-3409 | DOI: http://dx.doi.org/10.33448/rsd-v10i13.20548

Pinto, L. E. V., Gomes, E. D. \& Spósito, T. H. N. (2016). Uso de esterco bovino e de aves na adubação orgânica da alface como prática agroecológica. Colloquium Agrariae, 12, 75-81.

Pinheiro, J. I. (2015). Acúmulo e exportação de NPK em plantas de alface e coentro produzidas em sistema orgânico. 01-49.

R Core Team. R: A language and environment for statistical computing. Vienna, Austria: R Foundation for Statistical Computing, 2018. Available on: <https://www.rproject.org>. Accessed on: May. 2021.

Salles, J. S., Steiner, F., Abaker, J. E. P, Ferreira, T. L. \& Martins, G. L. M. (2017). Resposta da rúcula à adubação orgânica com diferentes compostos orgânicos. Revista de Agricultura Neotropical, 4 (2), 35-40.

Santana, M. J., Mancin, C. A. \& Ribeiro, A. A. (2016). Evapotranspiração e coeficientes de cultura para a alface e rúcula cultivadas em Uberaba-MG. Revista Inova Ciência e Tecnologia, 2, 7-13.

Santos, F. N., Saraiva, A. B., Pinto, F. E. N.; Cantanhede, J. D. \& Rodrigues, R. A. (2014). Desempenho agronômico do consórcio entre coentro e rúcula sob o sistema de cultivo orgânico. Horticultura Brasileira, 2, 2156-2163.

Sediyama, M. A. N., Santos, I. C. \& Lima, P. C. (2014). Cultivo de hortaliças no sistema orgânico. Revista Ceres, 61, 829-837.

Silva, G. S., Oliveira, R. A., Queiroz, N. L., Silva, M. N. B., Sousa, M. F. \& Silva, S. A. (2013). Desempenho agronômico de algodão orgânico e oleaginosas consorciados com palma forrageira. Revista Brasileira de Engenharia Agrícola e Ambiental. 17 (9), 975-981.

Silva, J. N., Bezerra Neto, F., Lima, J. S. S., Rodrigues, G. S. O., Barros Júnior, A. P., Chaves, P. A. (2017). Combinations of coriander and salad rocket cultivars in bicropping systems intercropped with carrot cultivars. Revista Caatinga, 30 (1), 125-135.

Silva, L. E. B., Barbosa, J. P. S., Santos, R. L.V., Souza, C. L, Santos, M. G. S., Costa, R. R. \& Brito, D. R. (2017). Uso de três tipos de adubos orgânicos de origem animal para o cultivo de coentro (Coriandrum sativum L.) e acelga (Beta vulgaris var. Cicla) em um organossolo. Revista Craibeiras de Agroecologia, $1(1), 1-4$

Spósito, T. H. N., Pinto, L E. V., Fabris, L. B. \& Nakagaki, A. L. G. (2015). Desenvolvimento da rúcula em cinco tipos de estercos em cultivo orgânico. Colloquium Agrariae, 11, 30-35.

Trani, P. E., Purquério, L. F. V., Figueiredo, G. J. B., Tivelli, S. W. \& Blat, S. F. (2014). Calagem e adubação da alface, almeirão, agrião d'água, chicória, coentro, espinafre e rúcula. 16.

Viana. C. S. Eficiência agroeconômica e aspectos fisiológicos no consórcio de rúcula (Eruca sativa miller) com espécies aromáticas condimentares. (2017). Dissertação (Mestrado em agronomia) - Universidade Federal do Ceará, 70.

Vieira, J. C. B., Puiatti, M., Cecon, P.R., Bhering, A. S., Silva, G. C. C. \& Colombo, J. N. (2014). Viabilidade agroeconômica da consorciação do taro com feijão-vagem indeterminado em razão da época de plantio. Revista Ceres, 61(2), 229-233.

Vione, E. L. B., Silva, L. S., Cargnelutti Filho, A., Aita, N. T., Morais, A. F. \& Silva, A. A. K. (2018). Caracterização química de compostos e vermicompostos produzidos com casca de arroz e dejetos animais. Revista Ceres, 65 (1), 65-73. 